\title{
Acute chest pain and tamponading left hemothorax: An unusual presentation of pulmonary arteriovenous malformation
}

Ira R. A. Goldsmith, MD, FRCS CTh, Ihab Ali, MBBS, MRCS, and Afzal Zaidi, MA, FRCS CTh

A 48-year-old man was admitted to the emergency department with sudden onset of severe, left-sided chest pain and signs of shock. En route to the hospital he was cold and clammy, tachycardic, with a differential pulse and blood pressure of 130/80 $\mathrm{mm} \mathrm{Hg}$ in the left arm and 70/- $\mathrm{mm} \mathrm{Hg}$ in the right arm. Because a dissecting aortic aneurysm was suspected, a contrast-enhanced computed tomographic scan of the chest was performed that showed a massive left-sided pleural collection with displacement of the mediastinum to the right but no evidence of an aortic dissection. The computed tomographic scan instead showed a high-density, contrast-enhanced pulmonary artery-venous malformation (PAVM) in the left lung (Figure 1) and a similar malformation in the midzone of the right lung (Figure 2). A large-bore chest drain was inserted into the left pleural cavity, which drained

\footnotetext{
From the Cardiothoracic Surgical Unit, ABM University Health Board, Morriston Hospital, Swansea, United Kingdom.

Disclosures: Authors have nothing to disclose with regard to commercial support. Received for publication Oct 27, 2010; accepted for publication Dec 2, 2010.

Address for reprints: Ira R. A. Goldsmith, MD, FRCS CTh, Consultant Thoracic Surgeon, Cardiothoracic Surgical Unit, Morriston Hospital, Swansea SA6 6NL, United Kingdom (E-mail: ira.goldsmith@abm-tr.wales.nhs.uk).

J Thorac Cardiovasc Surg 2011;141:833-4

$0022-5223 / \$ 36.00$

Copyright (c) 2011 by The American Association for Thoracic Surgery

doi:10.1016/j.jtcvs.2010.12.007
}

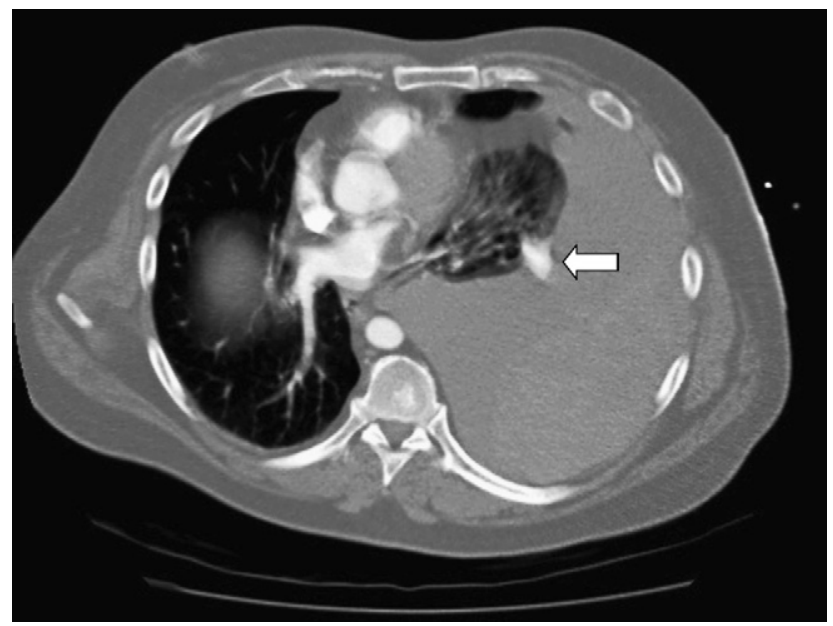

FIGURE 1. Contrast computed tomographic scan at the left atrium level showing a high-density lesion (arrow), indicating a pulmonary arteriovenous malformation. The mediastinum has shifted to the right owing to a large left pleural collection.
$3500 \mathrm{~mL}$ of dark blood. Because of this and the progressive hemodynamic instability, an emergency left thoracotomy was performed. At the operation, a fingerlike PAVM was seen on the surface of left lower lobe (Figure 3) that was excised with a linear stapler (Figure 4). The histologic diagnosis of PAVM was confirmed on microscopy. He made an uneventful recovery and 3 months later underwent an elective video-assisted thoracoscopic resection of the right PAVM. This was located in the inferior margin of the right upper lobe.

Bilateral PAVMs are rare, as is the presentation as severe chest pain and acute tamponading hemorrhage. Contrastenhanced computed tomographic scanning is the gold standard for establishing the diagnosis. Pulmonary angiography and embolization or, as illustrated by our case, surgical excision is the recommended treatment.

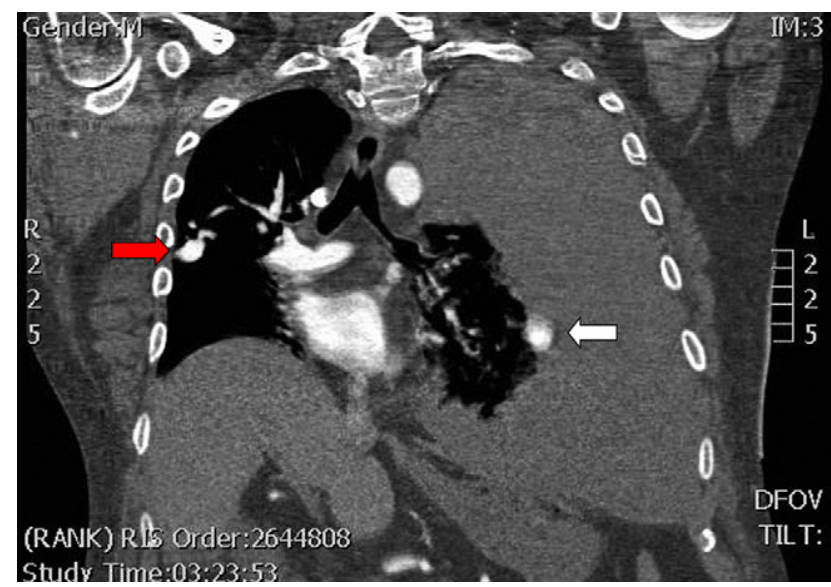

FIGURE 2. Coronal section of the chest computed tomographic scan shows a second contrast enhancing lesion (red arrow) in the right lung. 


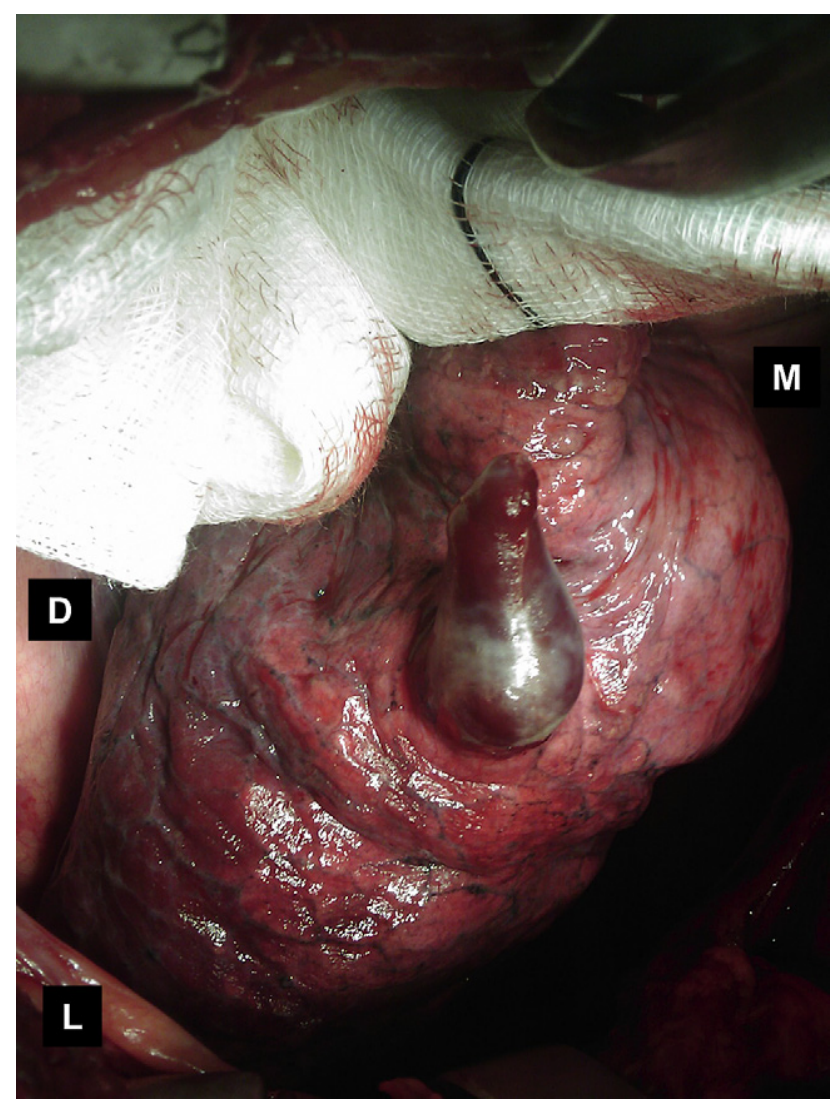

FIGURE 3. Pulmonary arteriovenous malformation arising from the lower lobe of the left lung. The bleeding tip of the malformation had sealed itself, whereas blood was seen swirling around in the malformation. $D$, Diaphragm; $L$, lateral chest wall; $M$, mediastinum.

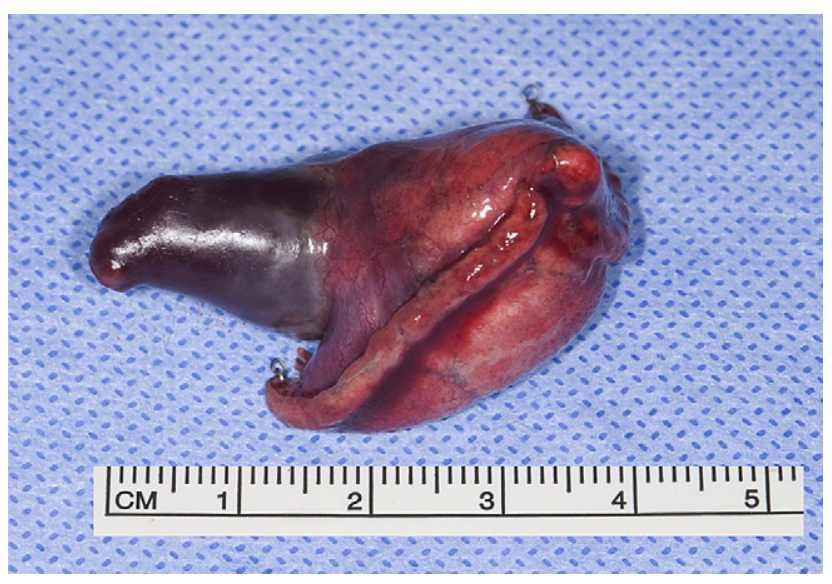

FIGURE 4. Resected left lower lobe pulmonary arteriovenous malformation. 